\section{Volatile sesquiterpenes emitted from leaves of Polygonum longisetum treated with jasmonic acid and its amide conjugates}

\author{
Shigeru TAMOGAMI, * Yasuhiro NARITA, \\ Shigeharu SuzUKI, Tomoyuki NisHIZAWA, \\ Hidetoshi HANAI and Masana NomA \\ Laboratory of Growth Regulation Chemistry, Department of \\ Biological Production, Akita Prefectural University, 241-7 \\ Kaidobata-Nishi, Shimoshinjo-Nakano, Akita, \\ Akita 010-0146, Japan
}

(Received March 2, 2007; Accepted May 7, 2007)

Sesquiterpenes, such as zingiberene, $\beta$-elemene, $\alpha$-bergamotene, $\beta$-caryophyllene and $(E, E)-\alpha$-farnesene were identified as volatile organic compounds (VOCs) from the leaves of Polygonum longisetum treated with jasmonic acid (JA) exogenously. Sesquiterpenes were emitted with $1 \mu \mathrm{M} \mathrm{JA}$, and their amounts and relative proportions altered according to the concentration. Experiments with silver thiosulfate (STS) suggested that ethylene might be involved in the JA-inducible emission of sesquiterpenes, but the responses of sesquiterpenes against STS were different among them. The conjugate of JA and 1-aminocyclopropane-1carboxylic acid (JA-ACC) was also active in emitting sesquiterpenes, while conjugates of JA and amino acids, such as Leu, Ile and Val, were inactive. Mevastatin suppressed almost all the sesquiterpenes, but zingiberene and $\beta$-elemene were not fully suppressed. It was suggested that JA might stimulate both the mevalonate and methylerythritol pathways in P. longisetum. (C) Pesticide Science Society of Japan

Keywords: jasmonic acid, JA, VOCs, ACC, Polygonum longisetum, sesquiterpene.

\section{Introduction}

Plants have chemical defense systems to protect themselves. Against pathogen attack, plants accumulate antifungal metabolites called phytoalexins. ${ }^{1)}$ In chemical defense systems, JA has been known to work as an endogenous potent signaling compound, ${ }^{2)}$ and exogenous application of JA elicits the production of secondary metabolites including phytoalexins. ${ }^{3,4)}$ In addition to

\footnotetext{
* To whom correspondence should be addressed.

E-mail: tamo.chem@akita-pu.ac.jp

Published online June 30, 2007

C Pesticide Science Society of Japan
}

the accumulation of defensive metabolites, plants emit VOCs as defensive chemicals that are thought to guide the parasitoids of feeding herbivores. ${ }^{5,6)}$ VOCs can be emitted not only by herbivore attack but also by exogenous application of $\mathrm{JA}^{7-9)}$ and its derivatives, including methyl jasmonate (MeJA), ${ }^{10,11)}$ and peptide conjugates. ${ }^{12)} \mathrm{JA}$ has been used as a useful elicitor in studying the roles of VOCs, and there is interest in how JA elicits the emission of VOCs.

VOCs have been studied with several plants including crops, ${ }^{7-12)}$ but we think that weeds might emit characteristic VOCs as selfdefensive systems, because they have to survive stiff competition in the natural habitat by developing efficient defensive systems. We have already found that $P$. longisetum emits several VOCs with citrus perfume by JA application. ${ }^{13)} P$. longisetum is a familiar weed in Japan and grows in colonies throughout the country. We confirmed that emission by JA was reproduced with plants grown in a laboratory chamber. We identified the VOCs from $P$. longisetum as sesquiterpenes, including zingiberene, $\beta$-elemene, $\beta$-caryophyllene, $\alpha$-bergamotene and $(E, E)$ - $\alpha$-farnesene as the main components. These sesquiterpenes from $P$. longisetum were all derived from the same precursor, farnesyl diphosphate (FDP). It is of interest whether the emission behavior of each volatile sesquiterpene is the same or differs during elicitation by JA. Thus, we planned to investigate the relative proportions of each component in VOCs from $P$. longisetum when changing JA concentrations. We also investigated the effects of compounds such as salicylic acid (SA) and ethylene, which have been suggested to be involved in JA-inducible emission of VOCs by lima beans. ${ }^{14)}$

Amide conjugates of JA have been known to induce self-defensive metabolites. For example, a conjugate of JA and Leu (JALeu) or JA and Val (JA-Val) has been shown to elicit phytoalexin production, ${ }^{15)}$ and a dipeptide conjugate of JA was able to elicit the emission of linalool from rice leaves. ${ }^{12)}$ JA-ACC has been found in arabidopsis, ${ }^{16)}$ and ACC (the metabolic precursor of ethylene) has been shown to accelerate the emission of JA-inducible VOCs. ${ }^{17)}$ Thus, JA-ACC might be active in the emission of sesquiterpenes from $P$. longisetum. The activities of these amide conjugates of JA were also investigated. Here we describe the results.

\section{Materials and Methods}

\section{Chemicals}

Salicylic acid, silver nitrate, sodium thiosulfate, $\beta$-caryophyllene and ACC were purchased from Wako Pure Chemical Industries (Tokyo, Japan). Mevastatin was purchased from Merck Ltd. Darmstadt, Germany). ( \pm )-JA, (-)-JA-Leu, (-)-JA-Ile and (-)JA-Val were prepared as described previously. ${ }^{18,19)}$ Racemic (士)JA-ACC was prepared from JA and ACC in the same manner as described above. ${ }^{1} \mathrm{H}-\mathrm{NMR} \delta\left(400 \mathrm{MHz}\right.$ in $\left.\mathrm{CDCl}_{3}\right): 0.92(3 \mathrm{H}, \mathrm{t}$, $J=7.7 \mathrm{~Hz}), 1.10(2 \mathrm{H}, \mathrm{m}), 1.52(3 \mathrm{H}, \mathrm{m}), 1.86-2.37(10 \mathrm{H}, \mathrm{m})$, 2.54 (1 H, m), 5.24 (1 H, m), 5.40 (1 H, m), 6.99 (1H, brs), 10.23 (1H, brs); ${ }^{13} \mathrm{C}-\mathrm{NMR} \delta\left(100 \mathrm{MHz}\right.$ in $\left.\mathrm{CDCl}_{3}\right): 14.0,17.7,18.0$, 
20.5, 25.5, 26.7, 33.4, 37.6, 38.4, 40.7, 54.0, 125.0, 133.9, 173.5, 176.9, 219.7; ESI-MS (negative) $m / z: 292.0[\mathrm{M}-\mathrm{H}]^{-}$, ESIMS/MS (mass of 292.0, negative) $\mathrm{m} / \mathrm{z}$ : 142.0, 100.0. ${ }^{1} \mathrm{H}$ and ${ }^{13} \mathrm{C}-$ NMR spectra were recorded using a JEOL ECP-400 with tetramethylsilane as an internal standard. Mass spectra were recorded using a PE-CIEX API-2000 Mass Spectrometer with an electrospray ionization (ESI) source.

\section{Plant material}

Seeds of Polygonum longisetum De Bruyn were collected at Tenno, Katagami, Akita in October 2005. The seeds were kept at $5^{\circ} \mathrm{C}$ for 2 weeks in moist commercial potting mixture (Hyponex Potting Soil, Hyponex Japan, Osaka, Japan). Plants were germinated and grown in a chamber (Biotron LPH-220S, Nippon Medical \& Chemical Instruments, Osaka, Japan) at $23^{\circ} \mathrm{C} / 12$-hr light / dark. After 6 to 8 weeks, fully expanded healthy leaves ( $c a .3$ to $5 \mathrm{~cm}$ long) were used for experiments.

\section{Incubation of leaves and collection of VOCs}

Leaves ( $c a .3 \mathrm{~cm}$ long) were detached and cut in half, and $2 \mathrm{~g}$ of the leaves were floated on an aqueous JA solution $(100 \mathrm{ml})$ in a flask $(300 \mathrm{ml})$ for $24 \mathrm{hr}$ (otherwise cited) under light at $25^{\circ} \mathrm{C}$. The leaves were separated from the solution and placed in a vial (100 ml) with $40 \mu \mathrm{l}$ of $n$-octane (as an internal standard, $20 \mathrm{mg}$ / $\mathrm{ml}$ in acetone) and sealed. Volatile compounds in the head space were collected by solid-phase micro-extraction with a fiber (65 $\mu \mathrm{m}$ Stable Flex PDMS/DVB, Supelco Co., PA, USA) according to the previous method. ${ }^{9)}$ A fiber was introduced into the head space through the septum and exposed for $30 \mathrm{~min}$ (at $25^{\circ} \mathrm{C}$ ). The fiber was injected into a gas chromatograph (GC) port for $5 \mathrm{~min}$. Leaves were floated on water as controls. The amount of volatile compounds was calculated from the peak areas in the chromatogram, based on that of $n$-octane. Each bar represents the mean \pm SE for three replicates in Figs. 2-6.

\section{SA and STS treatment}

To investigate the effects of $\mathrm{SA}, \mathrm{Ag}^{+}$, or mevastatin on JA-inducible VOCs, each substance was added to the JA solution used for the assay. The STS solution was prepared from $\mathrm{AgNO}_{3}$ and $\mathrm{Na}_{2} \mathrm{~S}_{2} \mathrm{O}_{3}$ (sodium thiosulfate) according to the protocols from Sigma-Aldrich (St. Louis, MO, USA).

\section{Apparatus and identification of the VOCs}

VOCs were analyzed by GC-MS (Perkin Elmer TurboMass Mass Spectrometer equipped with the Perkin Elmer Autosystem $X L$ GC) and GC-FID (Shimadzu GC-2010 with an FID detector). Identification and quantification were performed using Perkin Elmer GC-MS and Shimadzu GC-FID, respectively. Analytical conditions were as follows: Column: J\&W DB-5, $0.25 \mathrm{~mm}$ i.d. $\times 30 \mathrm{~m}, 0.25 \mu \mathrm{m}$ film thickness, flow rate: $1 \mathrm{ml} \mathrm{min}^{-1}(\mathrm{He})$, injection temperature: $150^{\circ} \mathrm{C}$, temp. program : $50^{\circ} \mathrm{C}(3 \mathrm{~min})$, with an increase of $10^{\circ} \mathrm{C} \mathrm{min}^{-1}$ to $200^{\circ} \mathrm{C}(3 \mathrm{~min})$, then an increase of $20^{\circ} \mathrm{C} \mathrm{min}^{-1}$ to $300^{\circ} \mathrm{C}$ (4 min), scan range: $\mathrm{m} / z$ 40-450. The same GC condition was used in both GC-MS and GC-FID. Compounds were identified by comparison of mass spectra with those in the literature, ${ }^{20)}$ and the NIST Mass Spectrum Search Program v. 1.5a (National Institute of Standards and Technology, Gaithersburg, Maryland). Identification of $\beta$-caryophyllene was also confirmed by comparison of their retention times and mass spectra with those of a standard.

\section{Results and Discussion}

\section{Identification of JA-inducible VOCs from leaves of $P$. longisetum}

GC-MS analysis of VOCs from leaves treated with JA $(100 \mu \mathrm{M})$ for $24 \mathrm{hr}$ gave a chromatogram consisting of zingiberene $\left(\mathbf{1}, t_{\mathrm{R}}\right.$ $15.18 \mathrm{~min}), \beta$-elemene $\left(\mathbf{2}, t_{\mathrm{R}} 15.25 \mathrm{~min}\right), \beta$-caryophyllene $\left(\mathbf{3}, t_{\mathrm{R}}\right.$ $15.76 \mathrm{~min}), \alpha$-bergamotene $\left(4, t_{\mathrm{R}} 15.90 \mathrm{~min}\right)$, sesquiphellandrene $\left(5, t_{\mathrm{R}} 16.00 \mathrm{~min}\right),(E)$ - $\beta$-farnesene $\left(6, t_{\mathrm{R}} 16.14 \mathrm{~min}\right), \alpha$-humulene $\left(7, t_{\mathrm{R}} 16.14 \mathrm{~min}\right),(E, E)$ - $\alpha$-farnesene $\left(8, t_{\mathrm{R}} 16.98 \mathrm{~min}\right)$ and an unknown compound $\left(\mathbf{9}, t_{\mathrm{R}} 15.90 \mathrm{~min}\right)$. Peaks of methyl 2-(E)hexenoate $\left(t_{\mathrm{R}} 7.21 \mathrm{~min}\right), \beta$-ocimene $\left(t_{\mathrm{R}} 8.89 \mathrm{~min}\right)$, indole $\left(t_{\mathrm{R}}\right.$ $13.44 \mathrm{~min})$ and $\alpha$-terpinolene $\left(t_{\mathrm{R}} 14.30 \mathrm{~min}\right)$ were also found in the chromatogram as minor components. No peak was found in the chromatogram from leaves treated with water. The detection limit was $10 \mathrm{ng}$ in the vial based on $n$-octane. Structures of the compounds (1)-(8) are shown in Fig. 1. $\beta$-Caryophyllene (3), $\alpha$ bergamotene $(4)$ and $(E, E)$ - $\alpha$-farnesene $(8)$ are already referred to as JA or MeJA-inducible VOCs in plants. ${ }^{9-11)} \beta$-Elemene has been found in VOCs emitted by pathogens in tobacco plants. ${ }^{21)}$ In the present study, we focused on eight major sesquiterpenes (1)-(8).

\section{Effects of concentrations of JA on sesquiterpenes from leaves of $P$. longisetum}

VOCs from leaves treated with different concentrations of JA (1, $5,10,50$, and $100 \mu \mathrm{M})$ for $24 \mathrm{hr}$ were investigated. The relative proportions of zingiberene (1), $\beta$-elemene (2), $\beta$-caryophyllene (3) and $(E, E)$ - $\alpha$-farnesene $(\mathbf{8})$ in VOCs from leaves treated with $5 \mu \mathrm{M}$ were similar to those in VOCs with $10 \mu \mathrm{M}$ (Fig. 2[A]). The relative proportions of these sesquiterpenes in VOCs with $50 \mu \mathrm{M}$ were similar to those with $100 \mu \mathrm{M}$ (Fig. 2[B]). In addition, at these high concentrations, significant amounts of $(E, E)-\alpha$-farnesene (8) were observed (Fig. 2[B]). These results showed that the relative proportion of sesquiterpenes in VOCs altered according to the concentrations tested.

\section{Effects of STS and SA on JA-inducible volatile sesquiter- penes}

Although no phytotoxic damage was observed in the leaves at higher concentrations of JA (50 and $100 \mu \mathrm{M})$, it was possible that significant emission of (E,E)- $\alpha$-farnesene (8) (Fig. 2 [B]) might occur through secondary effects by JA. It has been suggested that ethylene and salicylic acid (SA) are involved in the JA-inducible emission of VOCs from the leaves of lima beans. ${ }^{17)}$ Thus, the effects of STS (an inhibitor of ethylene action) on the JA-inducible emission of sesquiterpenes from the leaves of $P$. longisetum were investigated (Fig. 3[A]). The emission of sesquiterpenes decreased by STS $(200 \mu \mathrm{M})$, and then the significant emission of $(E, E)-\alpha$-farnesene $(8)$ disappeared. In addition, it was found that 


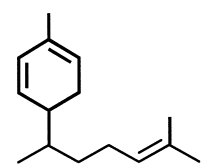

1

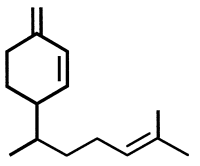

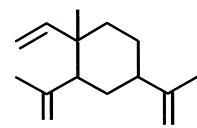

2

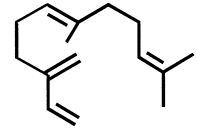

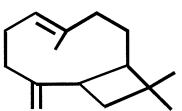

3

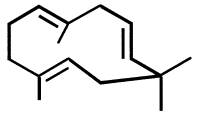

7

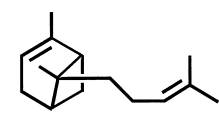

4

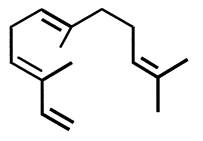

8

Fig. 1. Structures of sesquiterpenes identified in JA-inducible VOCs from $P$. longisetum. Compounds: zingiberene (1), $\beta$-elemene (2), $\beta$ caryophyllene (3), $\alpha$-bergamotene (4), sesquiphellandrene (5), (E)- $\beta$-farnesene (6), $\alpha$-humulene (7), $(E, E)$ - $\alpha$-farnesene (8).

inhibition degrees were different among sesquiterpenes. In particular, the emission of $\beta$-caryophyllene (3) was inhibited only about $55 \%$ by STS. Even the high concentration of STS $(1000 \mu \mathrm{M})$ was not able to block the emission of $\beta$-elemene (2), $\beta$-caryophyllene (3) and $(E, E)$ - $\alpha$-farnesene $(\mathbf{8})$, which were the main components of the sesquiterpenes emitted by $10 \mu \mathrm{M}$ of JA. The emission of sesquiterpenes by $100 \mu \mathrm{M}$ of JA with $200 \mu \mathrm{M}$ STS (Fig. 3[A]) was similar to that by $10 \mu \mathrm{M}$ of JA (Fig. 2[A]) in quantity. These results suggested that ethylene might be partially responsible for the difference between emission by $10 \mu \mathrm{M}$ of JA and that by $100 \mu \mathrm{M}$ of JA, although ACC (100 $\mu \mathrm{M}$ or $1000 \mu \mathrm{M})$ alone was inactive in the elicitation of VOCs (data not shown).
On the other hand, SA increased the JA-inducible emission of sesquiterpenes (Fig. 3[B]). It was interesting that the emission of $(E, E)$ - $\alpha$-farnesene $(8)$ and $\beta$-caryophyllene (3) was more effectively increased than other sesquiterpenes by SA. SA $(100 \mu \mathrm{M}$ or $1000 \mu \mathrm{M}$ ) alone was inactive in the elicitation of VOCs (data not shown). Considering the result that both ACC and SA were inactive, acceleration by ethylene and SA might work in parallel or after elicitation by JA.

4. The relationship between the incubation periods and JAinducible VOCs

Emissions of sesquiterpenes from leaves treated with JA solution
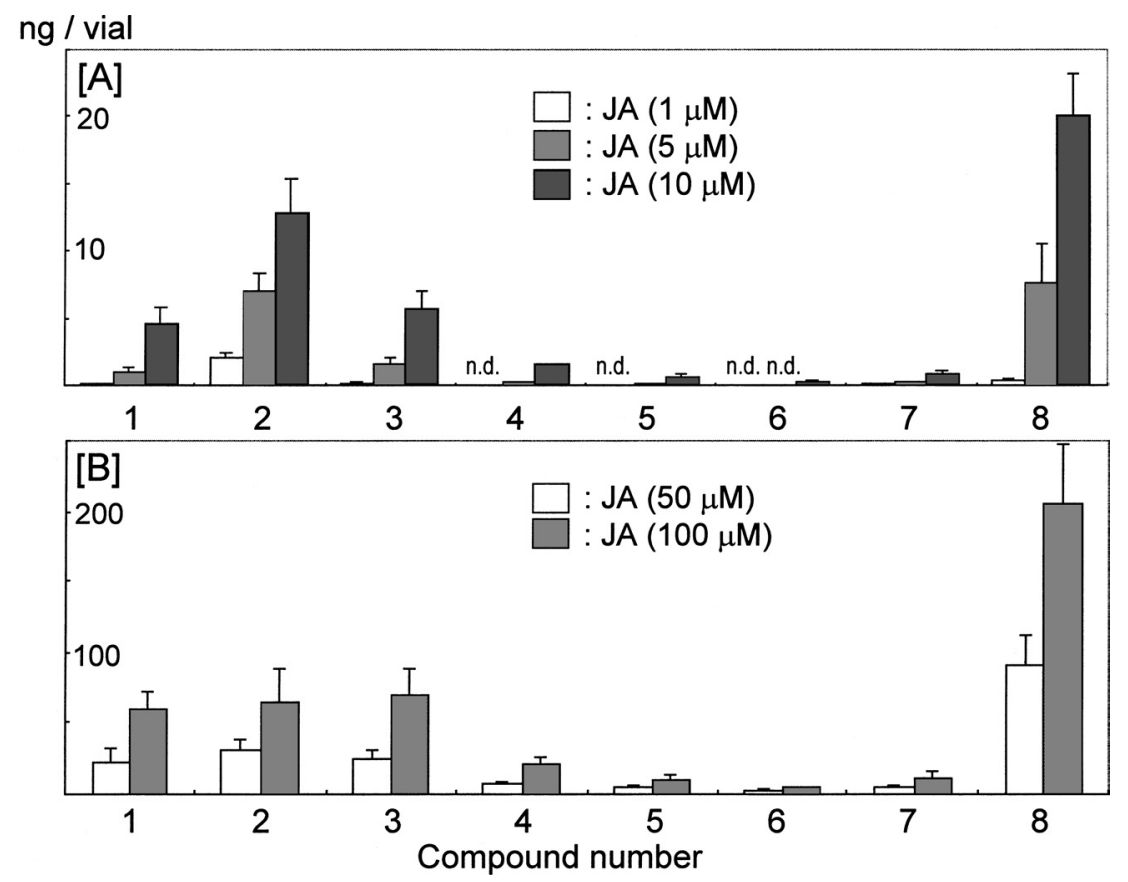

Fig. 2. JA-inducible VOCs from P. longisetum at different concentrations: [A] $1 \mu \mathrm{M}, 5 \mu \mathrm{M}$ and $10 \mu \mathrm{M}$ of JA, [B] $50 \mu \mathrm{M}$ and $100 \mu \mathrm{M}$ of JA. Compounds: zingiberene (1), $\beta$-elemene (2), $\beta$-caryophyllene (3), $\alpha$-bergamotene (4), sesquiphellandrene (5), $(E)$ - $\beta$-farnesene (6), $\alpha$-humulene (7), (E,E)- $\alpha$-farnesene (8). 

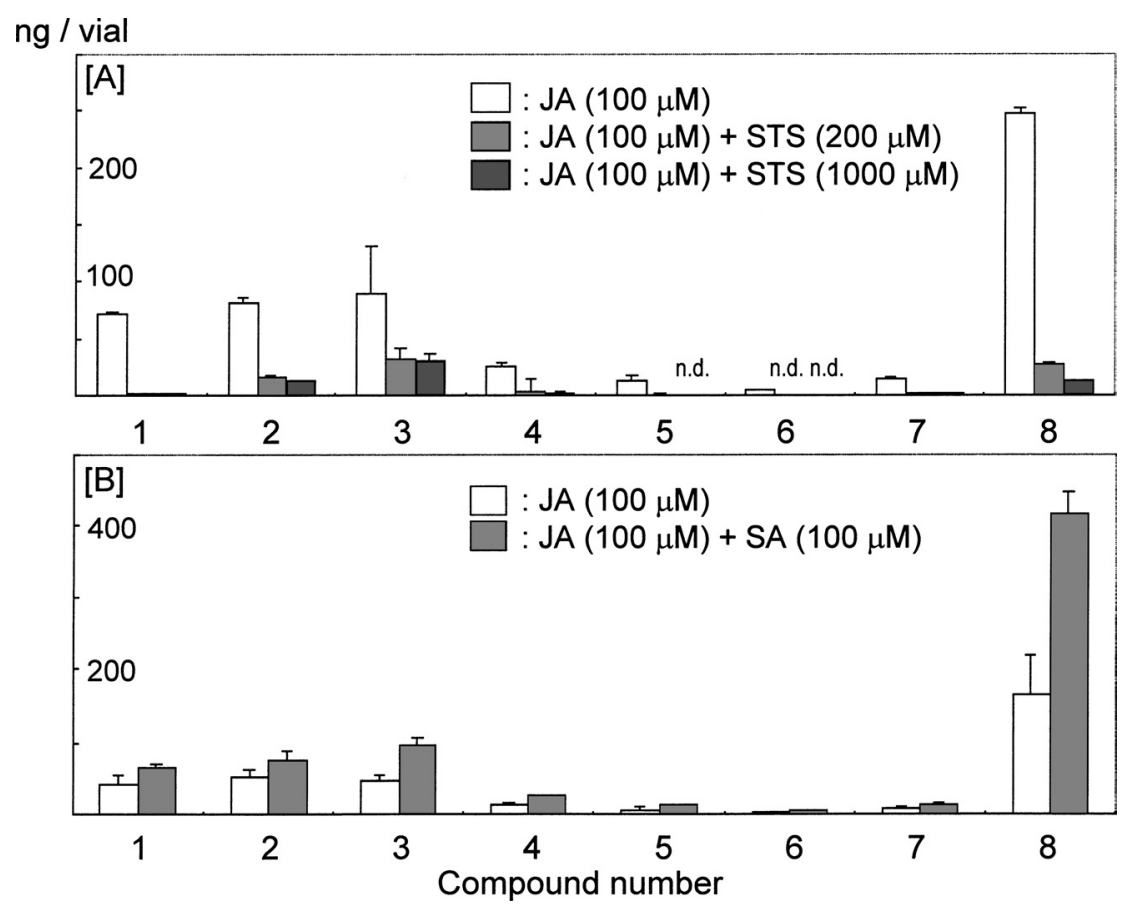

Fig. 3. Effects of STS and SA on JA-inducible VOCs from P. longisetum: [A] Effects of STS, [B] Effect of SA. Compounds: zingiberene (1), $\beta$-elemene (2), $\beta$-caryophyllene (3), $\alpha$-bergamotene (4), sesquiphellandrene (5), (E)- $\beta$-farnesene (6), $\alpha$-humulene (7), $(E, E)$ - $\alpha$-farnesene (8).

$(100 \mu \mathrm{M})$ for 3, 6, $14 \mathrm{hr}$ were investigated (Fig. 4). The released amount of $(E, E)$ - $\alpha$-farnesene (8) was significantly different from those of other VOCs with an incubation period of $14 \mathrm{hr}$ (Fig. 4 [B]), but no significant emission of $(E, E)$ - $\alpha$-farnesene $(8)$ was observed in VOCs with shorter incubation periods of $3 \mathrm{hr}$ and $6 \mathrm{hr}$
(Fig. 4 [A]). The amount of (E,E)- $\alpha$-farnesene $(8)$ was no more than that of $\beta$-caryophyllene (3) in VOCs at $6 \mathrm{hr}$ and $3 \mathrm{hr}$. The relative proportions of zingiberene (1), $\beta$-elemene (2), $\beta$-caryophyllene (3) and (E,E)- $\alpha$-farnesene (8) in VOCs with $100 \mu \mathrm{M}$ incubated for $6 \mathrm{hr}$ were similar to those in VOCs with $10 \mu \mathrm{M}$ incu-
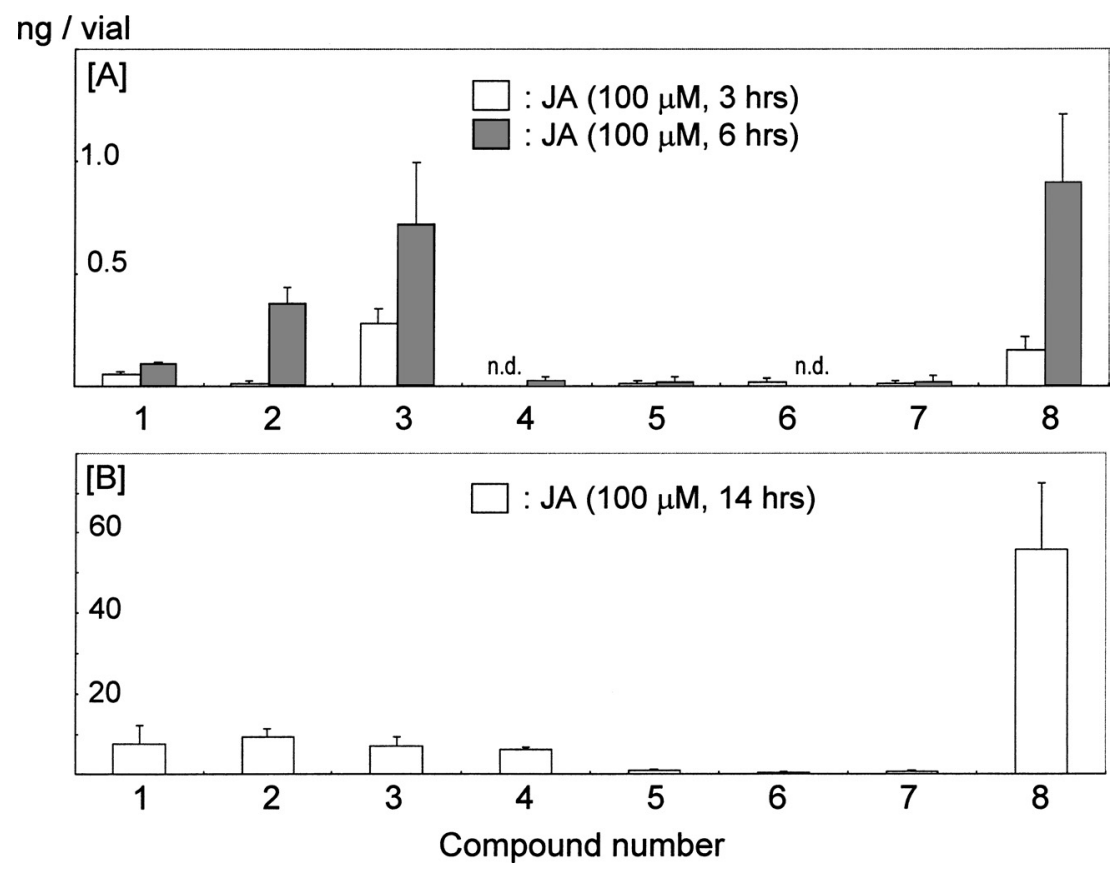

Fig. 4. JA-inducible VOCs from P. longisetum with different incubation periods: [A] $3 \mathrm{hr}$ and $6 \mathrm{hr}$ with $100 \mu \mathrm{M}$ of JA, [B] $14 \mathrm{hr}$ with $100 \mu \mathrm{M}$ of JA. Compounds: zingiberene (1), $\beta$-elemene (2), $\beta$-caryophyllene (3), $\alpha$-bergamotene (4), sesquiphellandrene (5), $(E)$ - $\beta$-farnesene (6), $\alpha$-humulene (7), (E,E)- $\alpha$-farnesene (8). 

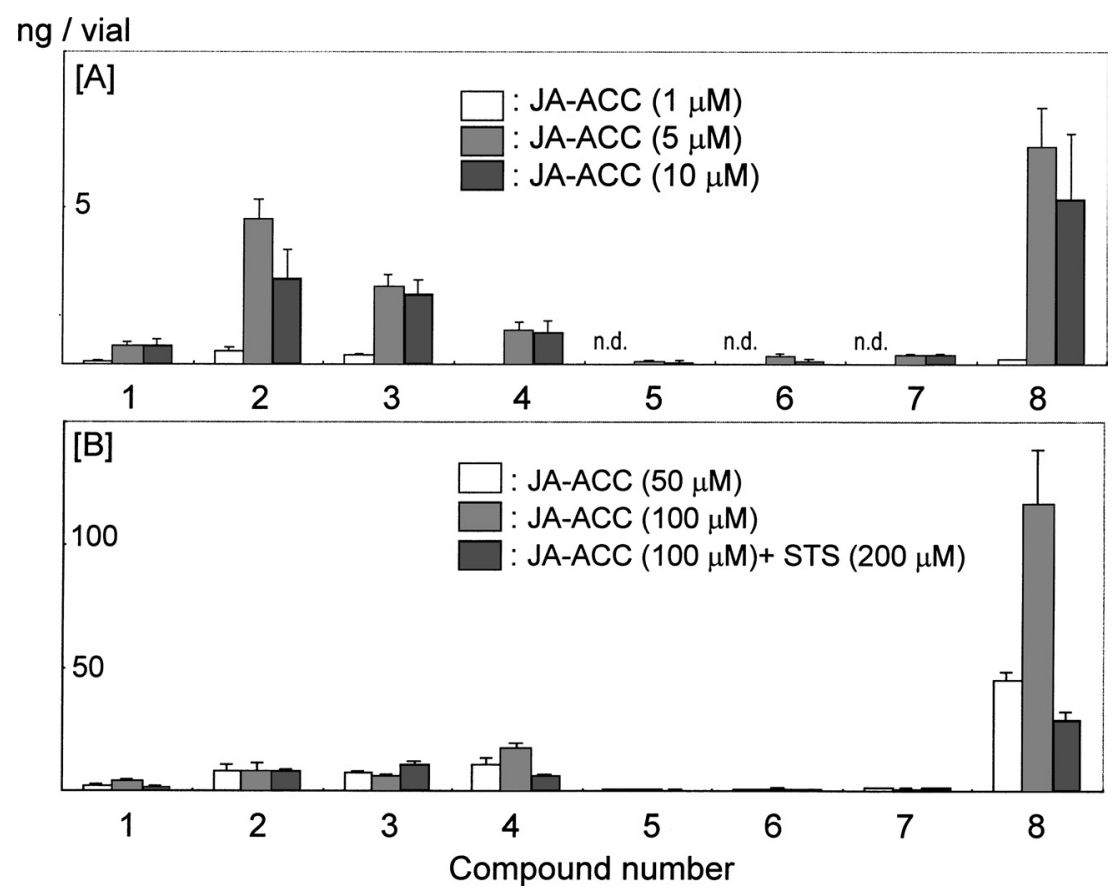

Fig. 5. (JA-ACC)-inducible VOCs from $P$. longisetum at different concentrations: [A] At $1 \mu \mathrm{M}, 5 \mu \mathrm{M}$ and $10 \mu \mathrm{M}$ of JA, [B] At $50 \mu \mathrm{M}$ and $100 \mu \mathrm{M}$ of JA. Compounds: zingiberene (1), $\beta$-elemene (2), $\beta$-caryophyllene (3), $\alpha$-bergamotene (4), sesquiphellandrene (5), $(E)$ - $\beta$-farnesene (6), $\alpha$-humulene (7), (E,E)- $\alpha$-farnesene (8).

bated for $24 \mathrm{hr}$ (Fig. 2[A]), although $\beta$-caryophyllene (3) was a little larger. It was suggested that short incubation periods or lower concentrations might yield similar relative proportions of sesquiterpenes in VOCs.

\section{Emission of VOCs by amide conjugates of JA}

Amide conjugates of JA have been found in plants and are suggested to work as derivatives of JA in the octadecanoid signaling pathway. ${ }^{22)}$ Amino acid conjugates of JA, such as JA-Leu and JAVal, have been shown to elicit phytoalexin production in rice leaves ${ }^{4,15)}$ and increase by wounding. ${ }^{23)}$ Another amide, JA-ACC has been found in Arabidopsis, ${ }^{16)}$ but there has been no information whether these derivatives would be active or not in the emission of VOCs. The present results showed that JA-ACC elicited the emission of sesquiterpenes as well as JA (Fig. 5), although JA-Leu, JA-Ile, and JA-Val were all inactive at $100 \mu \mathrm{M}$ (data not shown). In the relative proportions of sesquiterpenes induced by JA-ACC, there were few differences between that by $5 \mu \mathrm{M}$ and $10 \mu \mathrm{M}$ (Fig. 5[A]), or $50 \mu \mathrm{M}$ and $100 \mu \mathrm{M}$ without an increase of $(E, E)$ - $\alpha$-farnesene (8) (Fig. 5[B]), but relative proportions were different between JA-ACC and JA. Proportions of $\alpha$-bergamotene (4) with 50 and $100 \mu \mathrm{M}$ of JA-ACC (Fig. 5[B]) were a little higher than those of JA (Fig. 2[B]). JA-ACC resisted STS more than JA (Fig. 5[B]), that is, STS was not able to inhibit the emission of $\beta$-elemene (2) and $\beta$-caryophyllene (3) at all. It is possible that the ACC yielded from JA-ACC might affect on the resistance, although ACC applied exogenously showed no effects on the elicitation by JA (data not shown). These results indicated

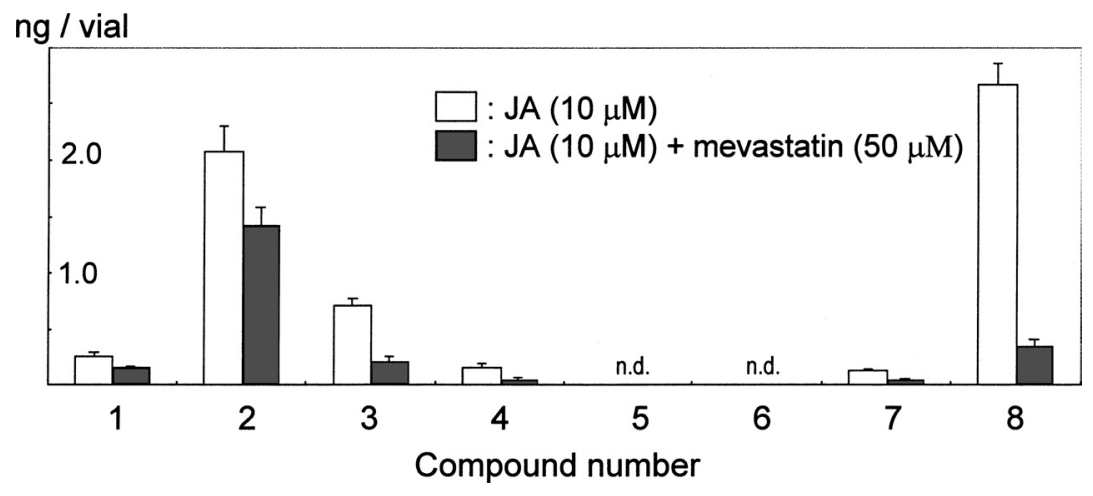

Fig. 6. Effect of mevastatin on the JA-inducible VOCs from P. longisetum. Compounds: zingiberene (1), $\beta$-elemene (2), $\beta$-caryophyllene (3), $\alpha$-bergamotene (4), sesquiphellandrene (5), (E)- $\beta$-farnesene (6), $\alpha$-humulene (7), $(E, E)$ - $\alpha$-farnesene (8). 
that JA-ACC might work differently from JA, and implied that JA-ACC might be an effective jasmonate signal in P. longisetum, though it has been suggested that JA-ACC was inactive in Arabidopsis. ${ }^{16)}$

6. Biogenesis of JA-inducible sesquiterpenes from $P$. longisetum

Terpenes are the major constituents of plants' defensive VOCs, and it is interesting how these VOCs are synthesized in plants. Recently, the dynamic pathway allocation of volatiles between monoterpenes and sesquiterpenes have been reported in VOCs from lima bean leaves, ${ }^{24)}$ and it was shown that an inhibitor of 3hydroxy-3-methylglutaryl-CoA (HMG-CoA) reductase reduced the emission of nerodiol-derived homoterpene. ${ }^{24)}$ The inhibitory activity of mevastatin (a HMG-CoA reductase inhibitor) on the JA-inducible emission of sesquiterpenes from leaves of $P$. longisetum was investigated. Interestingly, the emission of zingiberene (1) and $\beta$-elemene (2) was not fully reduced, but the emission of other sesquiterpenes was effectively suppressed (Fig. 6). This result implied that both the methylerythritol pathway (MEP) and mevalonate pathway (MP) might contribute to JA-inducible volatile sesquiterpenes in $P$. longisetum.

The present results showed that the emission of sesquiterpenes from $P$. longisetum was dependent on JA concentrations via probably ethylene action, and that sesquiterpenes might derive from both MEP and MP.

\section{References}

1) B. Deverall: "Phytoalexins," ed. by J. Baily and J. Mansfield, John Wiley and Sons Inc., New York, pp. 1-16, 1982.

2) E. Farmer and C. Ryan: Plant Physiol. 98, 995-1002 (1992).

3) H. Gundlach, M. Müller, T. Kuchan and M. Zenk: Proc. Natl. Acad. Sci. USA 89, 2389-2393 (1992).

4) R. Rakwal, S. Tamogami and O. Kodama: Biosci. Biotechnol. Biochem. 60, 1046-1048 (1996).

5) T. Turlings, J. Tumlinson and W. Lewis: Science 250, 1251-
1253 (1990).

6) T. Turlings, J. Loughrin, P. McCall, U. Röse, W. Lewis and J. Tumlinson: Proc. Natl. Acad. Sci. USA 92, 4169-4174 (1995).

7) J. Hopke, J. Donath, S. Blecher and W. Boland: FEBS Lett. 352, 146-150 (1994).

8) W. Boland, J. Hopke, J. Donath, J. Nüske and F. Bublitz: Angew. Chem. Int. Ed. 34, 1600-1602 (1995).

9) N. Obara, M. Hasegawa and O. Kodama: Biosci. Biotechnol. Biochem. 66, 2549-2559 (2002).

10) R. Halitschke, A. Keßler, J. Kahl, A. Lorenz and I. Baldwin: Oecologia 124, 408-417 (2000).

11) C. Saona, S. Brandner, P. Paré and T. Henneberry: J. Chem. Ecol. 27, 679-695 (2001).

12) S. Tamogami, M. Suzuki, H. Toshima, M. Hasegawa, O. Kodama and M. Noma: J. Pestic. Sci. 30, 225-227 (2005).

13) S. Tamogami, T. Nishizawa and M. Noma: Abstr. 31st Annu. Meeting Pestic. Sci. Soc. Jpn., p. 78, 2006 (in Japanese).

14) G. Arimura, R. Ozawa, T. Nishioka, W. Boland, T. Koch, F. Kühnemann and J. Takabayashi, Plant J. 29, 87-98 (2002).

15) S. Tamogami, R. Rakwal and O. Kodama: FEBS Lett. 401, 239-242 (1997).

16) P. Staswick and I. Tiryaki: Plant Cell. 16, 2117-2127 (2004).

17) G. Arimura, R. Ozawa, T. Nishioka, W. Boland, T. Koch, F. Kühnemann and J. Takabayashi: Plant J. 29, 87-98 (2002).

18) G. Büchi and B. Egger: J. Org. Chem. 36, 2021-2023 (1971).

19) R. Kramell, J. Schmidt, G. Schneider, G. Sembdner and K. Schreiber: Tetrahedron 44, 5791-5807 (1988).

20) P. Adams: "Identification of Essential Oil Components by Gas Chromatography: Quadrupole Mass Spectroscopy," Allured Pub. Corp., Carol Stream, IL, USA, 2001.

21) J. Huang, Y. Cardoza, E. Schmelz, R. Raina, J. Engelberth and J. Tumlinson: Planta 217, 767-775 (2003).

22) T. Kurumm, K. Bandemer and W. Boland: FEBS Lett. 377, $523-$ 529 (1995).

23) S. Tamogami and O. Kodama: J. Chromatogr. A 822, 310-315 (1998).

24) S. Bartram, A. Jux, G. Gleixner and W. Boland: Phytochemistry 67, 1661-1672 (2006). 